\title{
Editorial
}

\section{A importância da ciência e das universidades públicas na resolução de problemas sociais}

The importance of science and public

universities in solving social problems

\author{
Milena Pavan Serafim ${ }^{1}$ \\ University of Campinas | Campinas | SP | Brasil \\ milenaps@unicamp.br \\ https://orcid.org/0000-0002-7541-4182 \\ Rafael de Brito Dias 2 \\ ${ }^{2}$ University of Campinas | Campinas | SP | Brasil \\ rbdias@unicamp.br. \\ https://orcid.org/0000-0002-9702-2323
}

DOI: http://dx.doi.org/10.1590/S1414-40772020000100001

Este é um artigo publicado em acesso aberto sob uma licença Creative Commons https://creativecommons.org/licenses/by-nc/4.0/

O mundo vem assistindo com muita preocupação à proliferação do COVID-19, conhecido como Coronavirus. Esse momento ímpar da nossa história, transformado em evento global, aponta a nossa fragilidade enquanto estágio de civilização ao passo que reafirma a importância de elementos fundamentais: a ciência e a tecnologia. Não qualquer ciência ou qualquer tecnologia, mas sim àquelas que tratam e se voltam a problemas sociais.

Ao passo que os profissionais da área da saúde estão tratando os pacientes, os governantes estão decretando medidas de contingência da crise, buscando evitar a perda de vidas, o colapso dos sistemas nacionais de saúde e o arrefecimento máximo da economia, como medidas de transferência direta de renda, equipes de cientistas do mundo todo estão correndo contra o tempo na produção de vacinas que freiem a proliferação do vírus e de medicamentos que possam combater a doença. 
Trata-se de um episódio que, por sua natureza e dimensão, evidencia, ao mesmo tempo, a fragilidade das condições de existência no mundo contemporâneo e a relevância única da produção de conhecimento no enfrentamento dos grandes problemas que hodiernamente se apresentam. É precisamente sobre este ponto - a importância da ciência, da formação dos cientistas e das universidades públicas e dos institutos públicos de pesquisa - que versa este editorial.

Atingimos um estágio em que recorrentes problemas de alcance global, complexos e interconectados, geram desafios que impõem a necessidade de um inabalável compromisso para com a ciência e um empenho sistemático voltado à geração de novos conhecimentos por universidades e institutos de pesquisa. Os mesmos arranjos que elevaram o nível de produção global e concederam à parcela daqueles incluídos na cadeia trabalho-renda-consumo a satisfação de suas necessidades por meio de uma miríade fantástica de bens e serviços estão na base dos processos de rápida degradação ambiental observado ao longo do século XX e durante as primeiras décadas do século XXI.

A crise das instituições modernas - e da própria democracia - constitui outro grande desafio cujo enfrentamento requer novas abordagens, novos modelos e novos arranjos, nenhum dos quais pode ser desenvolvido e implementado sem o apoio de estudos, pesquisas, testes. A fome, o desemprego, a desigualdade, a exclusão social e o escasso acesso a serviços básicos são apenas alguns exemplos de temas que igualmente constituem desafios centrais no contexto de nosso longo percurso civilizatório, ora abalado por contingências de natureza econômica, política, social e sanitária. E ilustram questões que merecem atenção de cientistas e intelectuais, de governantes e tomadores de decisão.

A história nos ensina que alianças entre o Estado e a comunidade científica são capazes de gerar resultados impressionantes em curtos períodos de tempo. Foi assim, por exemplo, com o Programa Apollo, um dos mais emblemáticos marcos do avanço tecnocientífico durante o século XX. Foi assim também no Brasil. Por aqui a aliança entre o Estado e a comunidade científica teve consequências muito positivas, ainda que pouco usuais em nossa América Latina. Foi por meio dela que se viabilizou o protagonismo brasileiro no cenário agropecuário mundial, o desenvolvimento de sofisticadas técnicas de exploração de petróleo em águas profundas, as competências que possibilitaram o combate 
a doenças tropicais e "negligenciadas", o desenvolvimento tecnológico em setores estratégicos, como aeronáutica e tecnologias da informação e da comunicação...

Evidentemente, nenhum desses resultados foi decorrência do acaso ou da ordem natural das coisas. É produto de políticas públicas alinhadas à Política Científica e tecnológica e de estratégias de intervenção sofisticadas, apoiadas em conhecimento e sustentadas por profissionais altamente qualificado - pilares que foram construídos durante décadas em nosso país periférico, mas que têm sido recorrentemente abalados pelos cortes draconianos e pelo perverso projeto neoliberal-conservador do atual governo. A destruição das bases sobre as quais se produz ciência é claramente conduzida a um ritmo muito mais intenso do que aquele no qual elas foram construídas. Agir - e agir rápido - é, portanto, de crucial importância.

Talvez em outros tempos toda essa reflexão seria absolutamente desnecessária. E, quiçá, poderia um leitor de então receber até mesmo com certo estranhamento a esses argumentos. Mas certamente não hoje, na era das fake news, da pós-verdade, do terraplanismo ou do "nazismo de esquerda". Não agora, enquanto a ciência é atacada, assim como o serviço público, que em grande medida a sustenta. Agora, mais do que nunca, é época de resistência; pois sem ciência e sem conhecimento não há sequer futuro. Entretanto, é requerido que a produção de ciência e de conhecimento sejam relevantes aos problemas sociais.

O produtivismo acadêmico faz pouco para ajudar. Nunca se produziu tanto artigos científicos derivados de pesquisas. Há de se pensar em uma dinâmica de produção de conhecimento que vá além da simples satisfação de indicadores de produção. Muller (2018), em seu livro A Tirania das Métricas, retrata a conformação perversa da quantificação do trabalho por parte das instituições (esquema Taylorista de produzir e de ganho de eficiência) e a busca incessante do trabalhador para o alcance dessas métricas. Se essa relação e seus efeitos são questionados no âmbito industrial, com a ergonomia do trabalho, o que pensar no âmbito científico. Como foi apontado em outro editorial desta revista (o de julho/2019), não produzimos parafusos. O conhecimento relevante é aquele que se volta a questões que nos ajudam a compreender o passado, significar/ressignificar o presente e a moldar o futuro. Esses valores deveriam ser àqueles que efetivamente norteiam a comunidade de pesquisa. Esta deveria orientar sua forma de produzir mais por esses 
critérios e menos pelo afã de satisfazer métricas autocontidas, que tem como intuito organizar a distribuição de recursos, e cada vez menos relevantes no mundo real.

\section{Referência}

MULLER, Jerry. The tyranny of metrics. 2. ed. Princeton: Princeton University Press, 2018. 